\title{
Percursos e Percalços das pessoas com deficiência Intelectual em Salvador - Ba: Uma travessia para o mundo do trabalho
}

\author{
Routes and mishaps of people with intellectual disabilities in Salvador - Ba: A \\ crossing into the world of work
}

SILVA, Barbara Rocha. Mestranda em Educação profissional Científica e Tecnológica pelo Instituto Federal de Educação, Ciência e Tecnologia da Bahia- campus Salvador. E-mail: barbarafrs27@gmail.com

"Não sobrevive a espécie mais forte, mas a que se adapta à mudança".

\section{RESUMO}

A inclusão de estudantes com deficiência na Educação Profissional é um desafio tanto para estudantes quanto para as instituições de ensino. Esse artigo tem como objetivo apresentar os percursos e percalços da inclusão de pessoas com Deficiência Intelectual no mundo do trabalho por meio da Educação profissional até a aprovação da Lei nº 8213/1991, para tanto houve a necessidade de analisar a inserção sócio educacional dessa comunidade até a referida Lei. Trata-se de uma pesquisa bibliográfica com análise nas Leis $n^{\circ} 4024 / 61 ; n^{\circ}$ 5692/71; $n^{\circ} 4073 / 1942$ e decretos $n^{\circ}$ 7566/1909; esses materiais foram mediados por Milan (2011); Aguiar (2012); Capelline (2008); Carneiro (2015), entre outros. Esse estudo demonstra que houve avanços para as pessoas com deficiência, no que tange o exercício da cidadania, visto que foram incluídos no censo demográfico, saíram da condição de expostos e garantiram o direito de acesso e permanência na Educação Profissional e no mundo do trabalho. Ao confrontar alguns gráficos de órgãos reguladores de Salvador e do país com dados sobre os deficientes percebe-se ruídos entre essa conquista e a garantia do benefício de prestação continuada. Logo, faz-se necessário investigar se esta formação profissional e a garantia a uma vaga no mercado de trabalho possibilita uma formação para atender ao capital ou a emancipação humana.

Palavras-chave: Deficiência Intelectual; Educação Profissional; Mercado de Trabalho.

\section{ABSTRACT}

The inclusion of students with disabilities in Vocational Education is a challenge for both students and educational institutions. This article aims to present the paths and drawbacks of the inclusion of people with Intellectual Disabilities in the world of work through Professional Education until the approval of Law No. 8213/1991, therefore there was a need to analyze the socio-educational insertion of this community until the referred Law. This is a bibliographical research with analysis in Laws $n^{\circ}$ 4024/61; $n^{\circ}$. 5692/71; $n^{\circ} 4073 / 1942$ and decrees $n^{\circ} 7566 / 1909$; these materials were mediated by Milan (2011); Aguiar (2012); Capelline (2008); Carneiro (2015), among others. This study demonstrates that there have been advances for people with disabilities, regarding the exercise of citizenship, as they were included in the demographic census, left the exposed condition and guaranteed the right of access and permanence in Professional Education and in the world of work. When comparing some charts from regulatory agencies in Salvador and the country with data on the disabled, there is a difference between this achievement and the guarantee of the benefit of continued provision. Therefore, it is necessary to investigate whether this professional training and the guarantee of a place in the labor market enable training to serve capital or human emancipation.

Keywords: Intellectual Disability; Professional education; Job market. 
SILVA, B. R.. Percursos e Percalços das pessoas com deficiência Intelectual em Salvador - Ba: Uma travessia para o mundo do trabalho (2021).

Introdução

\section{Havia uma pedra no meio do caminho para o Progresso}

A história da Educação Profissional brasileira vem se delineando com momentos que incluem avanços e outros retrocessos. A legislação tem abarcado valores ora para atender aos anseios do capital e os organismos internacionais, ora para atender os movimentos sociais, vistos como minorias.

A trajetória social das pessoas com deficiência Intelectual é perpassada por mutilações socioculturais e emocionais, visto que na história das civilizações ocidentais, até a idade Moderna, esses grupos eram considerados seres quase abomináveis, devido a Ideologia predominante da Igreja. Ideologia aqui entendida como "Ideias e crenças que ajudam a legitimar os interesses de um grupo ou classe dominante, mediante sobretudo a distorção e a dissimulação de determinado fato social.”(EAGLETON,1997, p.08). Vale ressaltar que o conceito de Deficiência Intelectual utilizado na contemporaneidade, de acordo com o Glossário do site da Câmara dos deputados indica que essas pessoas apresentam:

Funcionamento intelectual significativamente inferior à média, com manifestação antes dos dezoito anos e limitações associadas a duas ou mais áreas de habilidades adaptativas, tais como: comunicação, cuidado pessoal, habilidades sociais, utilização dos recursos da comunidade, saúde, segurança, habilidades acadêmicas, lazer e trabalho. (BRASIL, s.d.)

Logo, deficiência Intelectual se revela como capacidade reduzida em algumas habilidades. Diniz (2007, p. 8) revela que a "concepção de deficiência como uma variação do normal da espécie humana foi uma criação discursiva do século XVIII, e desde então ser deficiente é experimentar um corpo fora de forma". Visto que, esse corpo está sempre sendo comparado com aquele dito normal. Respeitar esses grupos garantindo todas as condições que permitam potencializar as habilidades que não foram afetadas pela deficiência é fundamental para a construção de uma sociedade mais igualitária e democrática.

Opta-se por discutir a temática da Deficiência Intelectual até a aprovação da Lei de cotas $\mathrm{n}^{\circ}$ $8213 / 1991$, pois apesar dos debates sobre a identidade dessa comunidade, sejam por meio da medicina, da psicologia e pedagogia, ou da legislação, não havia dados de pessoas deficientes no censo do IBGE até 1991. Assim, para exemplificar alguns fatos, houve a necessidade de inserir dados do último censo demográfico da cidade de Salvador, uma vez que a autora do texto imersa na pesquisa de mestrado busca acompanhar o percurso dessa comunidade em Salvador.

No recenseamento geral de 1980 a categoria pessoa aparece, contudo não cita as pessoas com deficiência. O termo deficiente só aparece no ano de 1991, devido a aprovação da Lei ${ }^{\circ}$ 7853/1989 que determina a inserção desse grupo na categoria pessoas, o que revela que esses grupos não eram considerados cidadãos participativos até 1991.

Sabemos que a aprovação da Lei de Cotas, $n^{\circ}$ 8231/1991, para o mercado de trabalho demonstra os embates sociais de diferentes segmentos, os quais buscam retirar do acesso à educação Profissional para os deficientes o caráter assistencialista. Essa ação contribui para que as 
SILVA, B. R.. Percursos e Percalços das pessoas com deficiência Intelectual em Salvador - Ba: Uma travessia para o mundo do trabalho (2021).

pessoas com deficiência Intelectual se sintam construtoras de sua história, enquanto cidadãos ativos na sociedade. Afinal, "o corpo com deficiência somente se delineia quando contrastado com um representação de o que seria um corpo sem deficiência" (DINIZ, 2007, p. 8).

Algumas pesquisadoras apontam que empresas não estão atendendo ao que versa a Lei $n^{\circ}$ 8213/1991, um dos fatores para o não cumprimento da citada Lei é não ter pessoal qualificado para atuar com essas pessoas com deficiência Intelectual, o que demonstra uma fragilidade na legislação.

\section{Percurso Metodológico}

Esse artigo é de natureza qualitativa, mas apresenta alguns dados quantitativos. Tem como objetivo, apresentar os percursos e percalços da inclusão de pessoas com Deficiência Intelectual no mundo do trabalho por meio da Educação profissional até a aprovação da Lei nº 8213/1991, para tanto, houve a necessidade de analisar a inserção sócio educacional dessa comunidade até a referida Lei.

Para fundamentar essa escrita fez-se levantamento bibliográfico em artigos científicos e livros virtuais, sobre a temática da Deficiência Intelectual, mais especificamente aqueles que tratam do acolhimento educativo dessas pessoas em Salvador - BA, com foco na educação Profissional. Além disso, houve análise em Leis $n^{\circ} 4024 / 61 ; n^{\circ} 5692 / 71 ; n^{\circ} 4073 / 1942$, Decretos $n^{\circ}$ 7566/1909, entre outros, incluindo o Benefício de Prestação continuada, BPC, e assim pode-se verificar quais as conquistas dessa população ao longo do processo civilizatório. 0 artigo se apoia em autores como: Milan (2011); Aguiar (2012); Capelline (2008); Carneiro (2015), Diniz (2007), entre outros, que dialogam com a temática.

Assim, a partir do objetivo citado, busca-se compreender como foi a trajetória das pessoas com deficiência Intelectual em Salvador, desde a roda dos expostos até a aprovação da Lei de cotas $n^{\circ} 8213 / 91$, que garante acesso ao mercado de trabalho a este grupo por meio da sua capacitação profissional. A escrita traz um breve apanhado histórico do contexto mundial e enfatiza o que pessoas com deficiência vivencia até a Idade Moderna, quando começam a ter uma visibilidade social.

O desenvolvimento do texto se faz em quatro tópicos, além da introdução, havia uma pedra no meio do caminho para o progresso, acima e desse tópico sobre os métodos: $\mathrm{E}$ assim começa a seleção não - natural das espécies; E em Salvador- Bahia, como essa seleção se manifesta? Que venha o movimento da escola nova! Mas afinal, o que é esse Benefício de Prestação Continuada (BPC)? Por fim, as considerações finais induzem a continuar a investigação da inclusão das pessoas com deficiência Intelectual no mundo do trabalho.

E assim começa a seleção não-natural das espécies

"Os indivíduos com características mais adequadas para um determinado ambiente são mais propensos a sobreviver e se reproduzir". (autor desconhecido) 
SILVA, B. R.. Percursos e Percalços das pessoas com deficiência Intelectual em Salvador - Ba: Uma travessia para o mundo do trabalho (2021).

O itinerário das pessoas com deficiência segue marcado por momentos de infanticídio, segregação e exclusão, orientados pela seleção natural de exemplares aptos ou não para o convívio social e para o desenvolvimento de atividades laborais no sentido restrito da palavra. Evidenciando a dominação ideológica de alguns grupos sociais sobre os outros (DORE, 2006). Tais situações são vivenciadas num contexto de conflitos dogmáticos e científicos, no qual prevalece a ideologia da Igreja, entendida por Althusser (1988) como um aparelho ideológico de Estado.

Esse movimento revela que a sociedade ocidental ao migrar do modelo comunal para o privado não desenvolve o respeito às diferenças, ao contrário, tudo que foge ao padrão estabelecido pela classe hegemônica deve ser executado, exterminado. Segundo Gramsci (2001) sempre que houver disseminação de ideologias pelos instrumentos privados da hegemonia, teremos a consolidação desta. Na Idade Média os deficientes, dentre tantas situações, são levados à fogueira como revela Capelline (2008).

Durante a Inquisição, o Malleus Maleficarum (1482), manual de semiologia, era capaz de diagnosticar bruxas e feiticeiros; considerava sinais de malformação física ou mental como ligação com o demônio, o que levou muitas das pessoas com estas deficiências a fogueira da inquisição. (CAPELLINE, 2008, p.9)

Na Idade Moderna, século XVI, Paracelso, médico e Cardano, filósofo, são vistos como precursores a considerar a deficiência mental, entendida no contexto dessa escrita como intelectual, um problema médico, digno de tratamento. Eles demonstram preocupação com a educação da pessoa com deficiência.

$\mathrm{Na}$ Europa, a partir desse momento desenvolvem-se muitos estudos no campo da medicina contrapondo-se aos dogmas religiosos, os quais ainda são os mais aceitos, para conceituar deficiência. No século XVIII, segundo Capelline (2008), Foderé escreve o "Tratado do bócio e do cretinismo" revelando:

A ideia da hereditariedade da deficiência, o fatalismo genético do cretinismo. Segundo ele, o cretinismo implica, sobretudo, na degradação intelectual que será maior ou menor, conforme o acometimento da doença. Diferentes graus de retardo foram, então, associados a diferentes níveis de hereditariedade, justificando a segregação e a esterilização dos adultos afetados pelo bócio. (CAPELLINE, 2008, p.11)

Esse tratado leva a condição de deficiência para o campo da medicina. Thomas Wills, em Londres, século XVIII, também apresenta um argumento organicista para a deficiência Intelectual. No século XIX, Pinel assume que a deficiência Intelectual é uma condição biológica. $O$ vínculo com a medicina finda nas primeiras décadas do século XX, o conceito de deficiência segue atrelado à hereditariedade. Logo, começam a surgir escolas para crianças com deficiência mental. Em 1840 a escola Abendberg, busca recuperar cretinos e deficientes Intelectuais, focando no ensino pautado na construção da autonomia.

\section{E em Salvador - Bahia, como essa seleção se manifesta?}


A roda dos expostos ${ }^{1}$ da Santa Casa da Misericórdia em Salvador, criada em 1726, visa atenuar o problema das crianças, inclusive aquelas com deficiência abandonadas nas ruas e muitas vezes devoradas por cães e porcos (MILAN, 2011). Essa roda recebe filhos das escravas com a intenção de livrá-los da escravidão, filhos de viúvos que perdem a esposa no parto, filhos de casais pobres com muitos filhos e crianças com deficiência. Os pais das crianças com deficiência são vistos como pecadores tendo vergonha de apresentá-las à sociedade (MILAN, 2011). Essas crianças só ficam na Santa Casa até os 7 anos de idade, após essa idade começam a trabalhar em diferentes funções.

Importante ressaltar que a valorização da infância ocorre de fato entre os séculos XVIII e XIX passando a ser encarada como fase da vida. Antes disso, era comum ter meninos europeus de 7 anos nas forças armadas. Fato que foi apropriado aqui no Brasil, principalmente para os expostos, justificando a necessidade de uma qualificação para o trabalho destes que habitam a Santa Casa de Misericórdia (MILAN, 2011). Os meninos seguem para a agricultura, em escolas de ofício, internatos e para as guerras, já as meninas para o serviço doméstico. Esse é o marco das iniciativas do governo em atuar na Educação Profissional, no âmbito das instituições assistenciais (MILAN, 2011).

As Casas de Educandos e Artífices, foram criadas com a finalidade de acolher e ensinar um ofício aos meninos desvalidos e, dentre eles, os órfãos maiores de sete anos que residem na casa de expostos (CUNHA, 2000). Em 1824 a Constituição Outorgada traz em seu artigo n 179 que “ a instrução primária é gratuita a todos os cidadãos”. (BRASIL, 1824). Sabendo que negros e alforriados não são considerados cidadãos, será que os expostos eram?

Em Salvador, a Casa Pia de Órfãos de São Joaquim fundada em 1799, assume sede definitiva em 1825, atua com a mesma finalidade até 1910, sendo pioneira no Brasil a ter um projeto pedagógico e profissional, destinado, entre outros, aos expostos (MATTA,1996).

As casas de expostos recebem crianças com anomalias, Jannuzzi (2004) deduz que aquelas crianças cuja limitação Física, Sensorial ou Intelectual não compromete o exercício de atividade manual seguem encaminhadas para as casas de Educandos e Artífices, enquanto as mais comprometidas permanecem junto aos adultos, nos locais mantidos pela Santa Casa para doentes e alienados. A leitura de Jannuzzi (2004) demonstra que já havia um processo de seleção para o acesso à formação para o trabalho.

Em 1873 fundam-se alguns Liceus de Artes e Ofícios, o da Bahia, com sede em Salvador tem o mesmo objetivo e padrão do Liceu do Rio de Janeiro e São Paulo: formar mão-de-obra especializada para a indústria e o comércio.

\begin{abstract}
Trata-se de uma instituição que oferece gratuitamente aulas noturnas, abertas a todos, sem distinção de cor e classe social, solicitando apenas que os candidatos manifestem "condições morais" adequadas. Viabilizado por iniciativa do Estado e apoiado pelas agremiações profissionais da época - que mobilizam a sociedade para as doações, inclusive para a construção do edifício, o Liceu orienta sua estrutura educacional em função do ensino prático (aprendizado nas oficinas) e teórico (formação humanística). Seus modelos são as experiências anteriores do Rio de Janeiro e das escolas de
\end{abstract}

\footnotetext{
${ }^{1}$ Expostos ou excluídos aqui, são crianças que os pais por algum motivo não podiam criar, então eram deixadas nas portas de instituições de caridade, podendo ser normais ou deficientes.
} 
SILVA, B. R.. Percursos e Percalços das pessoas com deficiência Intelectual em Salvador - Ba: Uma travessia para o mundo do trabalho (2021).

artes e ofícios francesas, criadas nos séculos XVIII e XIX. (LICEU, 2015)

Este Liceu atua durante décadas na formação profissional baiana, juntamente com a Casa Pia e os Órfãos de São Joaquim (LIMA, 2012). Em 1874 o Asylo São Jorge de Deus é fundado, se tornando o primeiro espaço para atendimento às pessoas com deficiência mental, fenômeno a essa altura considerado problema de saúde pública. Em 1934 o governo da Bahia modifica o nome do Asylo para Hospital Juliano Moreira. A influência da medicina no cuidado dessas pessoas deficientes dura até 1930, contudo foi gradualmente substituída pela Psicologia e a Pedagogia a partir de 1903.

O marco da mudança desse cuidado se dá por meio das ações do médico Ulysses Pernambucano de Melo Sobrinho, nascido no Recife, que estuda medicina no Rio de Janeiro, se especializando em Psiquiatria, sob orientação do Prof. Juliano Moreira. "Sobrinho foi um dos primeiros médicos a estudar a Deficiência Mental no Brasil, enfatizando a necessidade do atendimento médico-pedagógico criando uma equipe multidisciplinar para trabalhar com as crianças com deficiência" (CAPELLINE, 2008, p.16). "Sua trajetória foi marcada pela defesa das minorias marginalizadas da sociedade, tais como: crianças com necessidades especiais, portadores de deficiência mental, negros e adeptos de religiões africanas" (BATISTA, 2017, s.p).

Em 02 de Junho de 1910 inaugura-se, oficialmente, na Bahia a Escola de Aprendizes e Artífices, decorrente da busca por mão de obra especializada, devido ao momento histórico vivenciado. Contudo, a maioria dos estudantes eram deserdados da sorte e necessitados da alimentação. A escola passa, então, a ser conhecida como a "Escola do Mingau". 0 artigo $6^{\circ}$ do decreto $n^{\circ} 7566 / 1909$ que determina a criação das Escolas de Aprendizes e Artífices revela que os alunos que buscassem dentro do prazo marcado a matrícula, deveriam possuir os seguintes requisitos, davam preferência os desfavorecidos da fortuna:

a) idade de 10 anos no mínimo e de 13 anos no máximo;

b) não sofrer o candidato moléstia infecto-contagiosa, nem ter defeitos que o impossibilitem para o aprendizado do oficio.

$\S 1^{\circ}$. A prova desses requisitos se fará por meio de certidão ou atestado passado por autoridade competente. (BRASIL, 1909)

Esse decreto representa um retrocesso na formação profissional das pessoas com deficiência Intelectual, pois demonstra que não há intenção de incluí-las no processo de formação profissional dessas escolas, haja vista que o candidato não deve ter "defeitos" que impossibilitassem o seu aprendizado. Logo a luta pela cidadania continua. Segundo o dicionário Soares Amora (2009) defeito é definido como: "Falta, deformidade, imperfeição, vício, mancha". Segundo Diniz (2007, p. 11) o desafio está em afirmar a deficiência como um estilo de vida, mas também em reconhecer a legitimidade de ações distributivas e de reparação da desigualdade, como também cuidados biomédicos". A exclusão desses educandos continua, a partir do movimento escolanovista surge uma luz no fim do túnel.

Que venha o movimento da Escola Nova.... 
SILVA, B. R.. Percursos e Percalços das pessoas com deficiência Intelectual em Salvador - Ba: Uma travessia para o mundo do trabalho (2021).

O movimento da Escola Nova, representa para o Brasil, na década de 1930, diversas reflexões nos âmbitos: econômico, político e social. Este movimento levanta a bandeira da educação como instrumento determinante para a construção de uma sociedade democrática. Visa o desenvolvimento do respeito à individualidade e a diversidade, pretende promover a integração social dos grupos marginalizados, gerando no seio da sociedade cidadãos críticos e reflexivos. Essa cidadania é construída por meio da escolarização de todos. Os preceitos dessa cidadania aparecem na constituição de 1934, no que tange a ampliação do ensino primário gratuito, capítulo II, título V, artigos 149 e 150 .

Devido aos estudos dos escolanovistas a psicologia passa a avaliar o nível de aprendizagem das crianças com deficiência, através dos testes de inteligência. Na década de 1930 a psicóloga e educadora Helena Antipoff, fundadora da sociedade Pestalozzi, chega a Minas Gerais para coordenar os cursos de formação de professores. Criam-se mecanismos de diagnósticos e classes especiais nas escolas públicas de Minas Gerais, as quais se estendem por todo o país. Contudo, segundo Capelline,

a influência do movimento escolanovista na Educação, no nosso país, acabou contribuindo para a exclusão dos diferentes das escolas regulares. Até mais da metade do século $X X$, o atendimento à pessoa com deficiência foi implementado através da institucionalização, da implantação de escolas especiais mantidas pela comunidade e de classes especiais nas escolas públicas para os variados graus de deficiência mental. (CAPELLINE, 2008, p.17)

A exclusão das pessoas diferentes citada acima por Capelline (2008), no que tange a educação Profissional dos Deficientes Intelectuais é verificada na Reforma Capanema, sob a Lei Orgânica n 4073/1942 que visa organizar o ensino industrial no Brasil objetivando alcançar a preparação profissional dos trabalhadores da indústria, das atividades artesanais, e ainda dos trabalhadores dos transportes, das comunicações e da pesca. (art $1^{\circ}$, lei $n^{\circ} 4073 / 42$ ). Já o art. n²9 destaca: "O candidato à matrícula na primeira série de qualquer dos cursos industriais, de mestria, ou técnicos, ou na única série dos cursos pedagógicos, deverá desde logo apresentar prova de não ser portador de doença contagiosas e de estar vacinado".

Art. $n^{\circ}$ 30. Deverá o candidato satisfazer, além das condições gerais referidas no artigo anterior, as seguintes condições especiais de admissão:

1. Para os cursos industriais:

a) ter doze anos feitos e ser menor de dezessete anos;

b) ter recebido educação primária completa;

c) possuir capacidade física e aptidão mental para os trabalhos escolares que devam ser realizados. (BRASIL, 1942)

A admissão nos cursos industriais exclui totalmente os deficientes, seja pelo quesito da educação primária, seja pela não aptidão mental revelando mais uma vez retrocesso na inclusão das pessoas com deficiência Intelectual em classes regulares, rumo a sua inserção no mundo do trabalho. Em 1955, a Organização Internacional do Trabalho (OIT) divulga a recomendação n. ${ }^{\circ} 99$ e destaca: "Os princípios e métodos de orientação vocacional e treinamento profissional, meios de aumentar oportunidades de emprego para os portadores de deficiência, emprego protegido e disposições especiais para crianças e jovens portadores de deficiência". 
SILVA, B. R.. Percursos e Percalços das pessoas com deficiência Intelectual em Salvador - Ba: Uma travessia para o mundo do trabalho (2021).

Esses princípios dialogam com a teoria do Capital Humano apresentada na década de 50-60 pelo economista estadunidense Theodore Schultz por meio de pesquisas desenvolvidas no Centro de Estudos Avançados das Ciências do Comportamento. Este economista revela dois determinantes para o capital humano, investir em si mesmo pela educação e pela saúde. (FRIGOTO, 2015)

A ideologia da classe hegemônica articula a teoria do capital humano com a educação e a empregabilidade, deixando a cargo do sujeito sua ascensão ou fracasso no mundo do trabalho. Aguiar (2012, p. 28) revela que "na perspectiva do capital prevalece a compreensão de que o paradigma da produção capitalista exige novos perfis profissionais e modelos de formação". Os quais devem se ajustar à qualificação profissional flexível e polivalente.

Seguindo estes parâmetros, a Lei n 4024/1961 é aprovada e em seu título II, art. nº 2 versa: "A educação é direito de todos e será dada no lar e na escola. O capítulo III, art. 47: "O ensino técnico de grau médio abrange os seguintes cursos: a) industrial; b) agrícola; c) comercial". (BRASIL, 1961). No título $X$, há as diretrizes para a Educação de Excepcionais: “Art. $n^{\circ}$ 88. A educação de excepcionais, deve, no que for possível, enquadrar-se no sistema geral de educação, a fim de integrá-los na comunidade". No título XI temos o art. $n^{\circ} 90$ e $n^{\circ} 91$ que evidencia a importância do papel da Assistência Social Escolar.

Nesse cenário há um crescimento no país, na década de 1960, das instituições de natureza filantrópica. A Associação de Pais e Amigos dos Excepcionais - APAE, é fundada em 1968, em Salvador e oferece atendimento aos deficientes Intelectuais, tendo em vista atender os pressupostos da Lei $n^{\circ}$ 4024/61. Entretanto, o centro de profissionalização é inaugurado em 1978 o que representa um hiato na formação profissional para o trabalho desses deficientes. Na Lei $n^{\circ} 5692 / 1971$, art. $n^{\circ} 9^{\circ}$ utiliza o termo deficiências física ou mental, garantindo a essa população:

Art. $9^{\circ}$ Os alunos que apresentem deficiências físicas ou mentais, os que se encontrem em atraso considerável quanto à idade regular de matrícula e os superdotados deverão receber tratamento especial, de acordo com as normas fixadas pelos competentes Conselhos de Educação (BRASIL, 1971).

0 artigo $9^{\circ}$ se manifesta como uma introdução para o que surge na década de 90 com o movimento "educação para todos", quando este começa a se organizar. Em 1975 a Organização das Nações Unidas aprova a Declaração dos Direitos das Pessoas Deficientes. Em 1983 a Convenção n 159 - Organização Internacional do Trabalho (OIT), art. $n^{\circ} 1$ e $n^{\circ} 2$ - revela: “[..] permitir que a pessoa deficiente obtenha e conserve um emprego e progrida no mesmo, e que se promova, assim a integração ou e reintegração dessa pessoa na sociedade" (OIT, 1983). 0 artigo $n^{\circ} 5$ "todos são iguais perante a lei sem distinção de qualquer natureza" e o art. 205 da constituição de 1988 afirma a educação como um direito de todos, dever do Estado e da família.

Para Veiga Neto e Lopes (2007, p. 954) as atuais políticas públicas de inclusão vêm desenhando uma cartografia em que os discursos como "Educação para todos", "Respeito à Diferença", tornam-se um solo fértil para que o Estado, governando os corpos, governe tudo; ou seja, "só isso já seria uma justificativa para que o Estado promova a inclusão, uma vez que estes deficientes saem da linha de invisibilidade social. E dessa forma, "o capitalismo se beneficia, pois, 
SILVA, B. R.. Percursos e Percalços das pessoas com deficiência Intelectual em Salvador - Ba: Uma travessia para o mundo do trabalho (2021).

as pessoas com deficiência cumprem uma função econômica como parte do exército de reserva e uma função ideológica mantendo-se na posição de inferioridade" (DINIZ, 2007, p.22).

Em 1989 foi aprovada a Lei $n^{\circ} 7.853 / 89$ que dispunha sobre a Política Nacional para a Integração da Pessoa Deficiente, prevendo a obrigatoriedade de se incluir nos censos nacionais questões específicas sobre os deficientes físicos e mentais.

Como deficientes mentais, foram definidas as pessoas com retardamento mental resultante de lesão ou síndrome irreversível, que se caracteriza por dificuldades ou limitações intelectuais associadas a duas ou mais áreas de habilidades adaptativas, tais como: comunicação, cuidado pessoal, autodeterminação, cuidados com saúde e segurança, aprendizagem, lazer, trabalho, etc. (IBGE, 2000, p. 22)

Por volta da década de $1980 / 90$ as políticas no âmbito da educação Profissional focam, mais fortemente, em atender as demandas do capital, com seu regime de acumulação flexível. A educação além de ser determinante no processo de fortalecimento do sistema passa a ser o fator que explica as diferenças de capacidade de trabalho, de produtividade e de renda. (CARNEIRO; AZEVEDO, p.06, 2015). Nessa época cresce no Brasil o fomento para rankings educacionais, os quais se preocupam com uma educação pautada no treino e no produto, não com a formação de um sujeito crítico e reflexivo, fortalecendo o ideal de qualificação polivalente e flexível.

Em um contexto, regido por políticas neoliberais, e pelas pressões de movimentos sociais, é aprovada a Lei $n^{\circ} 8213 / 1991$, visando garantir uma cota para a inserção do deficiente no mercado de trabalho. 0 que evidencia também uma imposição de organizações internacionais devido a Conferência Mundial de Educação para todos (1990). 0 art. nº 93 - a referida Lei versa:

Empresa com 100 ou mais funcionários está obrigada a preencher de dois a cinco por cento dos seus cargos com beneficiários reabilitados, ou pessoas com deficiência, na seguinte proporção: - até 200 funcionários............... 2\%; - de 201 a 500 funcionários......... 3\%; de 501 a 1000 funcionários........ 4\% - de 1001 em diante funcionários... 5\% (BRASIL, 1991).

A Lei representa um avanço significativo para a inclusão de pessoas com deficiência no mercado de trabalho, contudo constata-se que muitas empresas não cumprem tal regulamentação (FIORAVANTI, 2016). Ou quando cumprem tentam setorizar os fazeres de acordo com o que nos informa Silva (2011, p.117),

\begin{abstract}
o trabalhador cego é encaminhado para o trabalho com câmara escura, o surdo é encaminhado para atividades de design, as pessoas com deficiência mental para atividades manuais. A profissão ou atividades são definidas tendo como base a deficiência ou seu inverso: o desenvolvimento de uma pretensa capacidade devido a ausência, por exemplo, toda pessoa com deficiência visual é considerada talentosa para música, quem não tem a capacidade de ouvir é apto para desenho (SILVA, 2011, p. 117).
\end{abstract}

Fioravanti (2016) destaca também que as empresas que tentam cumprir a Lei de cotas para além dessa setorização apresentada por Silva (2011) não possuem pessoal habilitado para promover a inclusão de pessoas com deficiência Intelectual, haja vista as particularidades desse diagnóstico. 
SILVA, B. R.. Percursos e Percalços das pessoas com deficiência Intelectual em Salvador - Ba: Uma travessia para o mundo do trabalho (2021).

Isso acaba afastando essas pessoas do ambiente das empresas, que devido às barreiras atitudinais, são impedidas de exercer e usufruir sua cidadania plena. Diante desse fato algumas famílias de pessoas com deficiência temem, devido às incertezas da continuidade dos contratos, perder o BPC.

Mas, afinal, o que é esse Benefício de Prestação Continuada (BPC)?

O Benefício de Prestação Continuada da Assistência Social (BPC), é o direito garantido pela Constituição Federal de 1988, regulamentado pela Lei Orgânica da Assistência Social (LOAS), Lei nº $8.742 / 93$ e pelas Leis $n^{\circ} 12.435 / 2011$ e $n^{\circ} 12.470 / 2011$, que alteram dispositivos da LOAS; e pelos Decretos $n^{\circ}$ 6.214/2007, $n^{\circ}$ 6.564/2008 e $n^{\circ}$ 7.617/2011. Assegura 1 (um) salário mínimo [..] à pessoa com deficiência, de qualquer idade, com impedimentos de longo prazo, de natureza física, Mental, Intelectual ou Sensorial, que comprove não possuir meios de garantir o próprio sustento, nem tê-lo provido por sua família. Em ambos os casos, é necessário que a renda mensal bruta familiar per capita seja inferior a $1 / 4$ (um quarto) do salário mínimo vigente.

No ano de 2020, a Lei no 13982 de 02 de abril de 2020 versa em seu art. n 20-A: Em razão do estado de calamidade pública reconhecido pelo Decreto Legislativo $\mathrm{n}^{\circ} 6$, de 20 de março de 2020, e da emergência de saúde pública de importância internacional decorrente do coronavírus (Covid-19), o critério de aferição da renda familiar mensal per capita previsto no inciso I do $\S 3^{\circ}$ do art. 20 poderá ser ampliado para até $1 / 2$ (meio) salário-mínimo. A ampliação acontece de forma gradual, e atende aos critérios abaixo:

I - o grau da deficiência; II - a dependência de terceiros para o desempenho de atividades básicas da vida diária; III - as circunstâncias pessoais e ambientais e os fatores socioeconômicos e familiares que podem reduzir a funcionalidade e a plena participação social da pessoa com deficiência candidata ou do idoso; IV - o comprometimento do orçamento do núcleo familiar de que trata $\circ \S 3^{\circ}$ do art. 20 exclusivamente com gastos com tratamentos de saúde, médicos, fraldas, alimentos especiais e medicamentos do idoso ou da pessoa com deficiência não disponibilizados gratuitamente pelo Sistema Único de Saúde (SUS), ou com serviços não prestados pelo Serviço Único de Assistência Social (Suas), desde que comprovadamente necessários à preservação da saúde e da vida. $\$ 2^{\circ} 0$ grau da deficiência e o nível de perda de autonomia, representado pela dependência de terceiros para o desempenho de atividades básicas da vida diária, de que tratam, respectivamente, os incisos I e II do $\S 1^{\circ}$ deste artigo, serão aferidos, para a pessoa com deficiência, por meio de índices e instrumentos de avaliação funcional a serem desenvolvidos e adaptados para a realidade brasileira, observados os termos dos $\S \S 1^{\circ}$ e $2^{\circ}$ do art. $2^{\circ}$ da Lei $n^{\circ}$ 13.146, de 6 de julho de 2015 (BRASIL, 2020).

Outros critérios são descritos na referida Lei, são tantos critérios e crivos, os quais tendem a dificultar a garantia do benefício para quem realmente precisa, e tem direito adquirido pela constituição. Dados do Instituto Brasileiro de Geografia e Estatística (IBGE) apontam no último censo, em 2010, que a população de Salvador era de 2.675 .656 , desses $36,8 \%$ acusam rendimento nominal mensal per capita de até $1 / 2$ salário mínimo. Quando se trata da pesquisa com pessoas com alguma deficiência, foram entrevistadas 2331049 pessoas, as quais possuem 10 ou mais anos de idade, sendo que destas 35377 estavam na categoria pessoas com deficiência Intelectual. Vale 
SILVA, B. R.. Percursos e Percalços das pessoas com deficiência Intelectual em Salvador - Ba: Uma travessia para o mundo do trabalho (2021).

salientar que esse é o último ano de dados coletados pelo município de Salvador, disponíveis no site citado.

Os dados revelam que 2331049 pessoas foram entrevistadas e que destas 11303 são do sexo masculino e estão entre 15 e 19 anos e não estão ocupadas, essa idade é a fase de conclusão da Educação Básica, 3121 estão ocupadas. Quando busca-se o gênero feminino 16006 pessoas não ocupadas e 3971 ocupadas na mesma idade. Na fase entre 20 e 24 anos temos 6914 pessoas, também do gênero masculino, não ocupadas e 9025 pessoas ocupadas. Já do gênero feminino 11 071 estão ocupadas e 11351 não estão ocupadas, mostrando um crescente no acesso das mulheres em ocupação em relação aos homens, contudo precisa-se averiguar que tipo de ocupação estes dados se referem.

Quando a idade é de 25 a 29 anos temos 5538 pessoas não ocupadas e 14429 ocupadas todas referente ao gênero masculino. Enquanto o gênero feminino apresenta 16120 pessoas ocupadas contra 12110 não ocupadas. ${ }^{2}$ O Correio da Bahia, publica em 2019 dados da Síntese de Indicadores Sociais (SIS), com base em dados de 2018, divulgados pelo IBGE em novembro de 2019.

O Brasil atingiu um nível recorde de pessoas vivendo em condições de miséria no ano passado, 13.537 milhões de brasileiros, contingente maior do que toda a população da Bolívia. Na Bahia, quatro em cada dez baianos (42,9\% da população) e um em cada cinco soteropolitanos $(22,3 \%)$ vivem nessa condição. Em números absolutos, são 6,3 milhões de pobres e 1,9 milhão de extremamente pobres no Estado. (BAHIA, redacao@correio24horas.com. $\mathrm{br}^{3}$. 2020).

Salvador segundo IBGE tem uma população estimada 2.872.347 pessoas para 2019, e ao buscar informações dos beneficiários no portal da transparência encontramos 74400 pessoas atendidas pelo BPC, em média $2,59 \%$ da população da cidade.

Ao analisar os dados sobre o BPC confrontando-o com a população total da cidade de Salvador, surgem algumas inquietações: Esse dado representa de fato o número de pessoas que devem atender aos quesitos descritos na Lei Orgânica $n^{\circ}$ Lei $n^{\circ} 8.742 / 93$, e que apresentam as condições para ser beneficiário? Salientamos que a modificação dada pela Lei $n^{\circ} 13982$ de 02 de abril de 2020 não interfere nos dados da figura 02. Se as pessoas com deficiência estiverem imersas no mundo do trabalho, tendo a Lei ${ }^{\circ} 8231 / 91$ atendida, será que teríamos esses números? Essas indagações motivam a continuidade da pesquisa.

\section{Conclusões}

Buscamos compreender como foi a trajetória dos Deficientes Intelectuais em Salvador, no que tange acesso aos bens socioculturais acumulados pela sociedade, tendo com o principal viés o ensino Profissional, desde a roda dos expostos até a aprovação da Lei de cotas $n^{\circ} 8213 / 91$. Essa Lei

2 Mais informações sobre os dados disponível em: https://cidades.ibge.gov.br/brasil/ba/salvador/ pesquisa $/ 23 / 23612$ ?tipo $=$ ranking $\&$ ano $=2010 \&$ indicador $=23842$.

${ }^{3}$ Ver mais em: https://www.correio24horas.com.br/noticia/nid/bahia-tem-13-em-extrema-pobreza/. Acesso em 03 abr 2020 
SILVA, B. R.. Percursos e Percalços das pessoas com deficiência Intelectual em Salvador - Ba: Uma travessia para o mundo do trabalho (2021).

contribuiu para garantir acesso ao mundo do trabalho a esses indivíduos por meio da sua capacitação profissional, e com isso visibilidade social. Visto que essas pessoas só garantiram formalmente, seus direitos constitucionais de igualdade, no ano de 1989, com a Lei nº 7853.

Ao iniciar o levantamento de dados para esse artigo, nos deparamos com um novo mundo. A luta direta ou indireta dos deficientes para exercer sua cidadania, tendo os mesmos direitos dos sujeitos ditos "normais" é longa e foi marcada por infanticídios, marginalização e exclusão, uma vez que não estavam aptos a atender as expectativas ideológicas da classe hegemônica, e assim logo essa classe encontra uma maneira de retirá-los do caminho, para que não pudessem impactar na ordem para o progresso.

Diante da necessidade do mercado, seja por consumidores ativos, ou para garantia de exército reserva de mão-de-obra, marcado pela expropriação e precarização da força do trabalho pelo capital, mascarada na teoria do capital humano, essa população pode ser considerada como necessária para exercer algumas funções, e então poderiam passar por um crivo e serem aceitas em alguns setores do mercado de trabalho. Nesse cenário percebemos que a educação Profissional direcionada às pessoas com deficiência vincula-se às funções instrumentais e operacionais do mercado de trabalho. Essa atitude reforça o caráter da exclusão social e escolar vivenciada na trajetória histórica dessas pessoas. Esse estudo não se encerrou aqui, visto que avaliaremos como essas políticas de inclusão estão se reverberando em melhorias para esses grupos minoritários da população baiana, de 1991 até os dias atuais.

Após a aprovação da Lei de Cotas para o mercado do trabalho diversos pareceres e regulamentações surgiram, o próximo passo é investigar como estes estão sendo aplicados visando garantir a inserção das pessoas com deficiência Intelectual no mundo do trabalho. Ao avaliar o que traz a Figura 02, a qual revela como o Benefício de prestação Continuada tem chegado a Salvador é importante refletir sobre a relação inversamente proporcional, da oferta de emprego com a menor solicitação do BPC, e atentar-se para algumas variáveis que devem ser consideradas, uma delas é a forma como essas pessoas com deficiência tem sido acolhidas em suas potências dentro da empresa para continuar sua trajetória de forma equânime.

\section{Referências}

AGUIAR, Letícia Carneiro. FORMAÇÃO DOCENTE, POLÍTICA CURRICULAR E A REEDIÇÃO DA TEORIA DO CAPITAL HUMANO NO BRASIL. 2012. Disponível em: http:// periodicos.ufes.br/educacao/article/view/5372. Acesso em: 25 ago 2018.

ALTUSSER, L. P. Aparelhos Ideológicos de Estado. $7^{\text {a }}$ ed. Rio de Janeiro: Graal, 1988

AMORA, Antônio Soares. MINIDICIONÁRIO SOARES E AMORA DA LÍNGUA PORTUGUESA: $19^{\mathrm{a}}$ ed. São Paulo: Saraiva, 2009.

AZEVEDO, Fernando. et al. MANIFESTO DOS PIONEIROS DA EDUCAÇÃO NOVA (1932) E DOS EDUCADORES (1959). Disponível em: http: / /www.dominiopublico.gov.br/ download/texto/me4707.pdf. Acesso 15 nov 2018.

BATISTA, Augusto Chaves. ULYSSES PERNAMBUCANO DE MELLO SOBRINHO (1892-1943) PSIQUIATRA HOMENAGEADO EM 2010. Série Sinopses Biográficas, 2017. Disponível em: 
SILVA, B. R.. Percursos e Percalços das pessoas com deficiência Intelectual em Salvador - Ba: Uma travessia para o mundo do trabalho (2021).

http://www.espacociencia.pe.gov.br/?p=10747. Acesso em $20 \mathrm{dez} 2018$

BRASIL. CONSTITUIÇÃO DA REPÚBLICA DOS ESTADOS UNIDOS DO BRASIL (1934). Disponível em: http://www.planalto.gov.br/ccivil_03/Constituicao/

Constituicao34.htm. Acesso em 12 dez 2018.

BRASIL. CONSTITUIÇÃO DA REPÚBLICAFEDERATIVA DO BRASIL DE 1988. Disponível em: http://www.planalto.gov.br/ccivil_03/Constituicao/Constituicao.htm. Acesso em 20 dez 2018

BRASIL, Ministério da Educação. LEI no 4 024/1961 - LEI DE DIRETRIZES E BASES DA EDUCAÇÃO NACIONAL. Disponível em: http://www2.camara.leg.br/legin/fed/lei/

1960-1969/lei-4024-20-dezembro-1961-353722-publicacaooriginal-1-pl.html. Acesso em 20 dez 2018

BRASIL. LEI n 5692/1971 - LEI DE DIRETRIZES E BASES DA EDUCAÇÃO NACIONAL. Disponível em: http://www2.camara.leg.br/legin/fed/lei/

1970-1979/lei-5692-11-agosto-1971-357752-publicacaooriginal-1-pl.html. Acesso em 20 dez 2018

BRASIL. LEI $\mathrm{n}^{\circ}$ 8213/1991. LEI DE COTAS PARA DEFICIENTES. Disponível em: http://www.planalto.gov.br/ccivil_03/LEIS/L8213cons.htm. Acesso 20 dez 2108.

BRASIL. Ministério da Cidadania. Benefício de prestação Continuada. Lei Orgânica. Disponível em: http://mds.gov.br/assuntos/assistencia-social/beneficios-assistenciais/bpc. Acesso em 20 mar 2020.

BRASIL. LEI No 13.982, de 2 de ABRIL DE 2020. Disponível em: http:/ /www.in.gov. $\mathrm{br} / \mathrm{en} / \mathrm{web} / \mathrm{dou} /$-/lei-n-13.982-de-2-de-abril-de-2020-250915958. Acesso em 12 abr 2020

BRASIL, Câmera dos deputados. Glossário: O QUE É DEFICIÊNCIA INTELECTUAL. Disponível em: http://www2.camara.leg.br/a-camara/estruturaadm/ gestao-na-camara-dos-deputados/responsabilidade-social-e-ambiental/acessibilidade/oprograma/glossario.html. Acesso em $20 \mathrm{dez} 2018$.

BRASIL, Ministério da Educação e Cultura. DECRETO n 7566/1909 QUE CRIA A ESCOLA DE ARTíFICES. Disponível em: http://portal.mec.gov.br/setec/arquivos/

pdf3/decreto_7566_1909.pdf. Acesso em 17 dez 2018.

BRASIL. LEI No 7.853, DE 24 DE OUTUBRO DE 1989. Disponível em: http://www. planalto.gov.br/ccivil_03/leis/L7853.htm. Acesso em 11 nov 2018.

BRASIL. LEI ORGÂNICA DO ENSINO INDUSTRIAL: $n^{\circ}$ 4073/1942. Disponível em:http://www2.camara.leg.br/legin/fed/declei/1940-1949/decreto-lei-4073-30-janeiro-1942414503-norma-pe.html. Acesso em 18 nov 2018.

CAPELLINE, Vera Lúcia Messias Fialho (org); et al. EDUCAÇÃO ESPECIAL: HISTÓRIA, ETIOLOGIA, CONCEITOS E LEGISLAÇÃO VIGENTE. Bauru: MEC/FC/SEE, 2008. Disponível em: https://acervodigital.unesp.br/bitstream/

123456789/41616/5/Caderno\%202.pdf. Acesso em 10 ago 2018.

CARNEIRO, Marcos Torres; AZEVEdo, Márcio Adriano. A RELAÇÃO ENTRE EDUCAÇÃO E TRABALHO: O LUGAR DA EDUCAÇÃO NA INDÚSTRIA MODERNA E A TEORIA DO CAPITAL HUMANO. 2015. Disponível em:http:

//www.editorarealize.com.br/revistas/conedu/trabalhos/TRABALHO_EV045_MD1_SA6_ID5514_1008 2015002210.pdf. Acesso em 29 ago 2018.

DORE, Rosemary. GRAMSCI E O DEBATE SOBRE A ESCOLA PÚBLICA NO BRASIL. Cad. Cedes, Campinas, vol. 26, n. 70, p. 329-352, Set. / Dez. 2006.

DINIZ, Debora. O QUE é DEFICIÊNCIA. São Paulo: Brasiliense, 2007. Coleção primeiros passos; 324.

EAGLETON, Terry. IDEOLOGIA. UMA INTRODUÇÃO. São Paulo: Unesp, Boitempo, 1997. 
FRIGOTTO, Gaudencio. CONTEXTO E SENTIDO ONTOLÓGICO, EPISTEMOLÓGICO E POLÍTICO DA INVERSÃO DA RELAÇÃOO EDUCAÇÃO E TRABALHO PARA TRABALHO E EDUCAÇÃO. Revista Contemporânea de Educação, vol. 10, n. 20, julho/dezembro de 2015.

GRAMSCI, Antônio. CADERNOS DO CÁRCERE, VOLUME 2. Edição e tradução, Carlos Nelson Coutinho; co-edição, Luiz Sérgio Henriques e Marco Aurélio Nogueira. -2a ed. -Rio de Janeiro: Civilização Brasileira, 2001, p. 15-53.

IBGE. Instituto Brasileiro de Geografia e Estatística. TENDÊNCIAS DEMOGRÁFICAS NO PERÍODO DE 1950/2000. Disponível em:https://ww2.ibge.gov.br/home

/estatistica/populacao/censo2000/tendencias_demograficas/comentarios.pdf. Acesso 22 dez 2018.

JANNUZZI, G. de M. A EDUCAÇÃO DO DEFICIENTE NO BRASIL: DOS PRIMÓRDIOS AO INÍCIO DO SÉCULO XXI. Campinas: Autores Associados, 2004.

JANNUZZI, G. ALGUMAS CONCEPÇÕES DE EDUCAÇÃO DO DEFICIENTE. Rev. Bras. Cienc. Esporte, Campinas, v. 25, n. 3, p. 9-25, mai 2004a.

LICEU de Artes e Ofícios da Bahia (Salvador, BA). In: ENCICLOPÉDIA Itaú Cultural de Arte e Cultura Brasileiras. São Paulo: Itaú Cultural, 2018. Disponível em: http://enciclopedia.itaucultural.org.br/instituicao17451/liceu-de-artes-e-oficios-da-bahia-salvadorba. Acesso em: 20 de Dez. 2018. Verbete da Enciclopédia.ISBN: 978-85-7979-060-7.

LIMA, Claudia de Medeiros. LIMA, Márcio Santos. DE APRENDIZ A ESTAGIÁRIO: UM RESGATE HISTÓRICO NO ENSINO TÉCNICO PROFISSIONAL DO IFBA. VIICONNEPI. 2012. Disponível em: http://propi.ifto.edu.br/ocs/index.php/connepi/vii/

paper/view/1603/2212. Acesso 05 out 2015.

MATTA, Alfredo Eurico Rodrigues. CASA PIA COLÉGIO DE ÓRFÃOS DE SÃO JOAQUIM: DE RECOLHIDO A ASSALARIADO. $1996 . \quad$ Disponível em: https://ppgh.ufba.br/sites/ppgh.ufba.br/files/1996._matta_alfredo_eurico_rodrigues._casa_pia_co legio_de_orfaos_de_sao_joaquim._de_recolhido_a_assalariado.pdf. Acesso em 20 dez 2018

MILAN, Polliana. "UM ABRIGO PARA BEBÊS ABANDONADOS". 2011. Disponível em: https: / / www.gazetadopovo.com.br/vida-e-cidadania/um-abrigo-para-bebes-abandonadosbz3wyr2ezy5uwepk6fn338d3i/. Acesso em 18 dez 2018.

NETO, Veiga Alfredo. INCLUSÃO E GOVERNAMENTALIDADE. In: LOPES, Corcini Maura. Educ. Soc., Campinas, vol. 28, n. 100 - Especial, p. 947-963, out. 2011. Disponível em:http://www.cedes.unicamp.br. Acesso em 20 mar 2014.

OIT. Organização Internacional do Trabalho. CONVENÇÃO $\mathrm{n}^{\circ}$ 99, $1955 . \quad$ Disponível em:http://www.ame-sp.org.br/site/index.php?option=com_content\&view= article\&tid=259\&ltemid=72. Acesso em $14 \mathrm{dez} 2018$.

OIT. Organização Internacional do Trabalho. CONVENÇÃO No 159, 1983. Disponível em:http://www.trtsp.jus.br/geral/tribunal2/LEGIS/CLT/OIT/OIT_159.html. Acesso em 16 dez 2018.

SILVA, Izaura Maria de Andrade. POLÍTICAS DE EDUCAÇÃO PROFISSIONAL PARA PESSOAS COM DEFICIÊNCIA. 2011.

Disponível

em:http://www.bibliotecadigital.ufmg.br/dspace/bitstream/handle/1843/FAEC-

8M4M2S/tese_izaura_silva_2011.pdf?sequence=1. Acesso em 07 dez 2018 